\title{
A comparison of simulated one-way and shuttle avoidance in an automated apparatus'
}

BRIAN M. KRUGER, PETER F. GALVANI, and JUDSON S. BROWN, UNIVERSITY OF IOWA, Iowa City, Iowa 52240

The fully automated shuttle box employed in two experiments permitted the comparison within one apparatus of performance under a simulated one-way condition and the usual shuttle condition. Animals in the simulated one-way condition always ran from a white compartment into a black compartment, but alternated their direction of locomotion, as did the shuttle animals. In both experiments, animals run under the simulated one-way condition showed superior per cent avoidance performance relative to the shuttle animals. The results were compared with those obtained in other one-way avoidance and shuttle studies.

Efficient instrumental avoidance behavior is usually acquired by rats within about a dozen trials in both the one-way avoidance apparatus (Theios, 1963; Theios \& Dunaway, 1964) and the straight runway (Beecroft \& Bouska, 1967). In the shuttle box, however, even under optimum conditions, rats take nearly 100 trials to reach a level of about $90 \%$ avoidance (Moyer \& Kurn, 1964; Theios \& Dunaway, 1964) and under less favorable circumstances never become highly proficient even with substantially prolonged training (Brush, 1966).

Two at tributes of the shuttle-box task can be blamed for much of its difficulty. First, since shock is presented in both compartments, fear becomes classically conditioned not only to the nominal CS, the buzzer or light, but also to the visual, auditory, olfactory, and tactual cues indigenous to each box. Inasmuch as the cues of one box are much like those of the other, the total stimulus complex on the to-be-entered side evokes nearly as strong a fear reaction as the avoided side, at least during the early stages of training. Consequently, the amount of fear reduction following an avoidance reaction is relatively sight and the reinforcement for avoiding is minimal. Not until the fear evoked by the indigenous cues has been substantially reduced through extinction will a response that terminates only the nominal CS be followed by an appreciable decrement in fear.

Second, the administration of shock in each compartment and the reinforcement provided by escape therefrom serves to produce diametrically opposed locomotor gradients and hence a conflict situation of the avoidance-avoidance type (Miller, 1944). Under such conditions, a successful avoidance reaction cannot occur unless the tendency to leave the "start" side is momentarily increased, as by the addition of the CS to the aggregate of indigenous stimuli, or by a momentary weakening of the competitive tendency, perhaps through oscillatory fluctuations, or both. In the one-way apparatus, by contrast, only a single avoidance gradient is present so that locomotion does not depend upon the momentary strengthening of the relevant tendency or on the temporary weakening of a competitive one.

It follows from the foregoing that avoidance responding in the shuttle box (and, indeed, also in the one-way apparatus) can be increased by making the stimuli on the "start" side as distinctive as possible relative to those on the "goal" side. This would minimize the effect of the oppositely directed avoidance tendency and increase the reinforcement provided by fear reduction consequent to a successful anticipatory response. A corollary of this principle, specific to the shuttle box, is that the "start" side stimuli should be made as invariant as possible from trial to trial regardless of which physical compartment is serving momentarily as the "start" side.

Previous investigators have shown that manipulations of the general sort described above do indeed enhance shuttle-box avoidance. Thus Baum (1965), Tenen (1966), Baum and Bobrow (1966), McCleary (1966), and Olton and Isaacson (1968) have found that avoidance learning can be facilitated by such strategems as having $S$ run in only one direction with respect to the external environment, by having $S$ dropped from a jumped-onto goal platform back to the start section, and so on.

In the experiments reported here an attempt has been made to provide, in a shuttle box, all of the distinctive and unambiguous stimulus characteristics of the one-way device while retaining, for the purpose of automatic control, two-way responding. Thus, $S$ always runs out of a white-walled, grid-floored "start" box into an entirely black "goal" chamber with a smooth floor. Shortly before the beginning of the next trial the black chamber is transformed automatically into a white-willed, grid-floored "start" box. This is accomplished by withdrawing the black walls, ceiling, and smooth floor from around S, leaving him on a grid floor in an all-white environment. The originally white start box is converted to a black goal box during the intertrial interval. Since $S$ must reverse his direction of movement from trial to trial the device is two-way with reference to the extern.l cuvironment but simulates the distinctive stimulus properties of one-way boxes and runways. Our apparatus was patterned, in pirt. after one designed by Stampfl (see Levis, 1966) in which the floor of the starting side (though not the walls and ceiling) was pulled out from under the $S$.

In the two experiments reported here comparisons have been made between the simulated one-way condition and two slightly different versions of the standard shuttle-box procedure.

\section{APPARATUS}

Figure 1 presents a schematic cut-away drawing of one of the two identical start-goal boxes comprising the apparatus. Within the $1 / 2$-in. plywood exterior shell of each box there is a stationary compartment $\left(4 \times 83 / 4 \times 14 \frac{1}{2}\right.$ in. $)$ with side walls of white translucent plastic, a grid floor (3/32 in. diam stainless steel rods spaced $1 / 2$ in. between centers) over a white excretion-collection tray of translucent plastic, and a clear plastic side-hinged ceiling door. At the front there is a black guillotine door and at the back there is a black plastic wall with a 2 -in. loud speaker mounted behind centrally located holes. The white compartment can be 


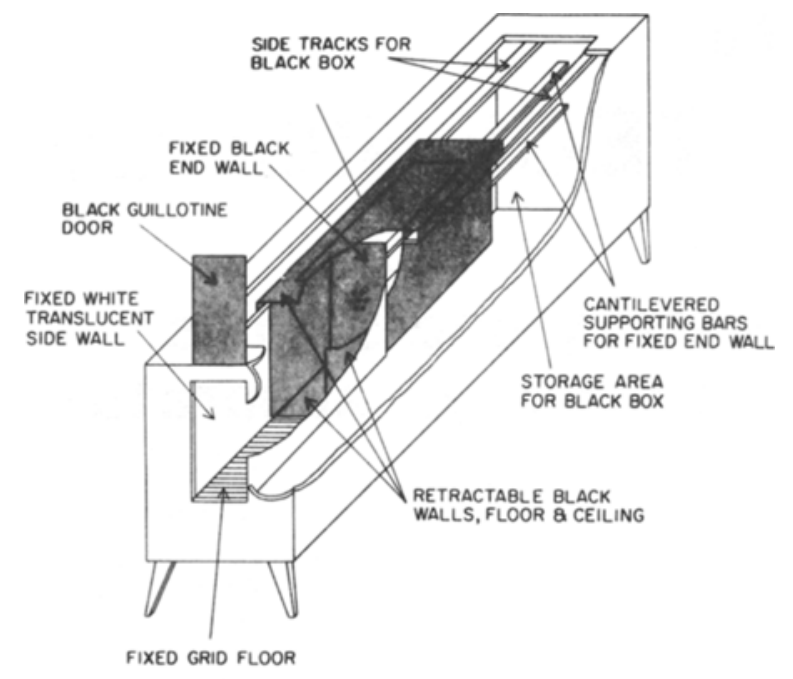

Fig. 1. A cut-away drawing of the essential features of the start-goal box used in the simulated-one-way avoidance and shuttle tasks. The black box is depicted in a partially retracted position.

illuminated from below by two 25-W showcase bulbs the brightness of which can be adjusted by means of a commercial incandescent dimmer. This essentially white compartment can be converted to an all black compartment ( $33 / 4 \times 7.7 / 8 \times 14 \frac{1}{2}$ in.) by moving an openended box with opaque black walls in from the storage area behind the stationary black end wall. The box hangs from, and rolls on, tracks at the sides. Its floor and side walls, and the mounting flanges for its rollers, which extend sideways from its ceiling, are made of one continuous piece of 1/16-in. thick, black-painted aluminum. The ceiling with its upward-opening hinged door is of $1 / 4$-in. black plastic. The cantilevered bars which support the back wall extend through the black box, when it is in storage, to the back wall of the surrounding wooden box. Thus, when the black box is moved back into the storage area, the fixed back wall acts, relatively speaking, as a plunger "pushing" the rat off the solid floor onto the grid floor, unless, of course, the rat steps off by itself. The two main boxes are placed front-to-front for automated shuttle-box studies, but the device can be converted into an automated runway by inserting a suitably constructed alley between the boxes.

Power for moving the black boxes and guillotine doors is supplied by $24-\mathrm{V}$ dc motors, with friction drives for the doors and rack-and-pinion drives for the boxes. Forward and reverse movements of the boxes are limited by stationary snap-action switches and cams mounted on top of the boxes. Upward and downward movements of the doors are limited by the use of light beams, photoelectric cells, and associated control equipment. The sequencing of events during operation is controlled by electronic timers, pulse-formers, and auxiliary relays.

Two infrared beams are located $1 \frac{1}{2}$ in. and 3 in. above the grid floor immediately inside the doors; another infrared beam is located $9 \mathrm{in}$. inside the compartments and $1 \frac{1}{2}$ in. above the grid floor. The latency of the rat's response, timed with an electronic clock, is measured from the instant the guillotine doors begin to rise until the rat interrupts the infrared beams immediately inside the door of the opposite compartment. The doors descend when the rat breaks the infrared beam inside the compartment.

The $60-\mathrm{Hz}$ ac shock was controlled by a variable autotransformer and fed to the grid through the series combination of a $10 . K$ resistor and a grid scrambler (Davis
Scientific Instruments, Model $255,300 \mathrm{rpm}$ ). The output of the autotransformer was continuously monitored by a 2000$\mathrm{ohm} / \mathrm{V}$ ac meter.

\section{EXPERIMENT 1}

In the first study, performance in the simulated one-way (SOW) apparatus was compared with that in the same apparatus when used much like a regular shuttle device. In the SOW condition, the black box in which the rat spent the intertrial interval was withdrawn into storage at the start of each trial and avoidance became possible when the guillotine door was raised. The opposite black box always moved from storage into its "goal box" position during the last few seconds of the intertrial interval. The rats in the "shuttle group" spent the intertrial interval in a white, but unlighted box with grid floor. At the start of a trial, the lamps under the white plastic floor were lighted, the tone came on, and the door opened, permitting $S$ to run in to the other, unilluminated white box. During the latter part of the intertrial interval, the black box in the to-be-entered section first moved out of its storage position into the "goal box" position and then immediately back into storage. These seemingly irrelevant movements of the opposite-side box in the shuttle condition provided the shuttle animals with auditory and vibratory cues much like those experienced by the SOW animals. Thus on each trial both groups heard a sequence of two box movements: the SOW animals heard the opposite box move into position and then their own move out; the shuttle animals heard the opposite box move in and then heard it (rather than their own) retract. Such sequences of stimuli are not ordinarily present in automated shuttle boxes and would be expected to improve the performance of the Ss in the shuttle group.

\section{Method}

The Ss were 40 female hooded rats, 96 to 111 days old, from the colony maintained by the Psychology Department of the University of Iowa. Twenty rats were randomly assigned to each of the two groups, SOW and Shuttle. Three rats were discarded and replaced by new Ss, two due to equipment failure (one in each group), and one in the SOW group due to failure to respond within $15 \mathrm{~min}$ on the second trial. Each $\mathrm{S}$ was given 50 massed acquisition trials in a single session.

The CS complex consisted of the increase in illumination attending the withdrawal of the black boxes plus a $5000-\mathrm{Hz}$ sine-wave tone. The illumination in the boxes that served as the CS was adjusted to approximately $15 \mathrm{ft}-\mathrm{c}$, as determined by a Weston Illumination Meter (Model 756). When the light was off, the illumination dropped to an unmeasurable level. The sound-pressure level of the starting box was approximately $68 \mathrm{~dB}$ with the tone on and $60 \mathrm{~dB}$ with the tone off. These measurements were made with a General Radio Company Sound Level Meter ( $C$ weighting) and are relative to 0.0002 dynes $/ \mathrm{cm}^{2}$.

The sequence of events on each trial for the SOW group was as follows: The first box (opposite the box containing S) started to move into its goal position $3 \mathrm{sec}$ before the second box (containing S) began to withdraw. The 5000- $\mathrm{Hz}$ tone and lights came on simultaneously with the start of the movement of the second box, the doors started up $4 \mathrm{sec}$ after the start of the movement of the second box, and a 50-V shock (approximately $0.5 \mathrm{~mA}$ ) came on $5 \mathrm{sec}$ after the doors started up. Thus, the effective CS-UCS interval was about 5 sec. The intertrial interval was $30 \mathrm{sec}$. The interruption of the infrared beam in the compartment into which the rat escaped or avoided terminated both the tone and shock and started the guillotine doors down. This sequence of events was the same for the shuttle group, except that, as described above, only the box opposite the one containing $\mathrm{S}$ moved. 


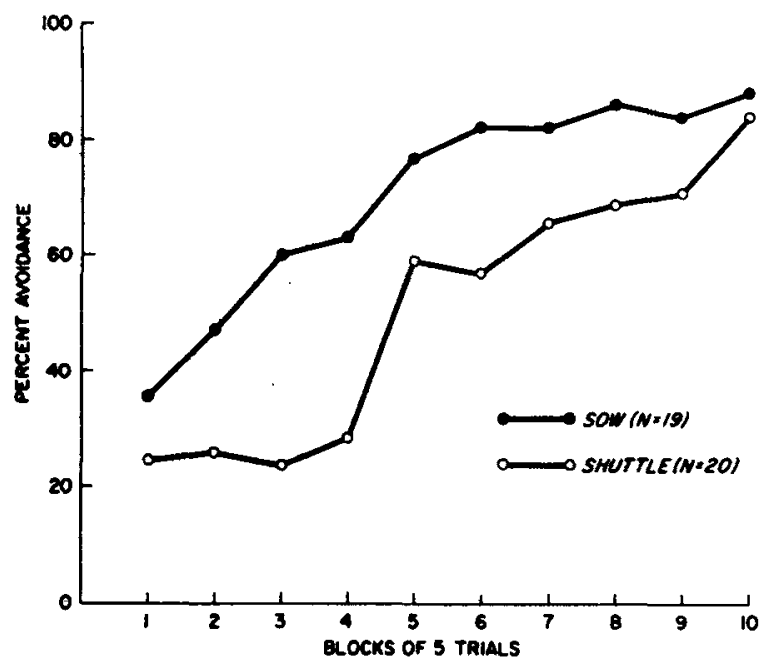

Fig. 2. The per cent of avoidances in Experiment 1 for the SOW and Shuttle groups over trials.

\section{Results}

One $S$ in the SOW group failed to avoid over the 50 training trials. It was observed by $\mathrm{E}$ that this $\mathrm{S}$ vigorously resisted the withdrawal of the black box on each trial. This competing behavior perhaps interfered with avoidance learning. The data collected from this $S$ have been eliminated from all analyses reported for Experiment 1, leaving 19 Ss in the SOW group.

The course of acquisition for both groups is shown in Fig. 2 where per cent avoidance is plotted against blocks of five trials. Analysis of variance indicated that the Groups effect $(F=10.48$, $d f=1 / 37, p<.005)$, and the Trials effect $(F=29.66, d f=9 / 333$, $\mathrm{p}<.001)$ were both significant but not the Trials-by-Group interaction $(F=1.81$, df $=9 / 333, p>.05)$. Mean reciprocal latencies are shown in Fig. 3. The analysis of variance performed on these data revealed that the Groups effect $(F=21.41$, $\mathrm{df}=1 / 37, p<.001)$, the Trials effect $(F=24.72$, $\mathrm{df}=9 / 333$, $\mathrm{p}<.001)$, and the Group-by-Trials interaction $(\mathrm{F}=2.95$, $d f=9 / 333, p<.005)$ were all significant .

The means and standard deviations for both groups on four additional measures of avoidance learning are presented in Table 1. Although none of the differences is significant, the simulated one-way condition produced superior avoidance performance relative to shuttle training in every case.

\section{Discussion}

It is apparent from Figs. 2 and 3 that the performance of the SOW group was superior to that of the Shuttle animals. Moreover, while the per cent avoidance curves for the SOW and Shuttle groups converge over trial Blocks 6-10 (Fig. 2.), the reciprocal latency curves (Fig. 3) diverge, with the SOW group showing much faster responding. Nevertheless, the Ss in the SOW group performed less well than Ss in conventional one-way devices. Comparison data are found in a study by Theios and Dunaway (1954) who report that a one-way avoidance group reached $100 \%$ avoidance in the third 5-trial block. Similarly, Beecroft and Bouska (1967), using a 6-ft runway, found that percentages of avoidances approached 100 after approximately 35 trials. Evidently, our SOW arrangement was better than the conventional shuttle procedure but was less efficient than the true one-way device. Differences in frequency of handling and in being able 10 run in a consistent direction with respect to extra-maze cues may contribute to the superior performance levels of one-way Ss.

One noteworthy result was that the shuttle Ss performed much
Table 1

Means and Standard Deviations

\begin{tabular}{|c|c|c|c|c|c|}
\hline & & $\begin{array}{l}\text { Shuttle } \\
\text { Training }\end{array}$ & $\begin{array}{l}\text { Simulated } \\
\text { One-Way }\end{array}$ & $t$ & $\mathbf{P}$ \\
\hline Subjects & $\mathbf{N}$ & 20 & 19 & & \\
\hline $\begin{array}{l}\text { Trial of First } \\
\text { Avoidance }\end{array}$ & $\stackrel{M}{\mathrm{SD}}$ & $\begin{array}{l}6.40 \\
5.46\end{array}$ & $\begin{array}{l}3.37 \\
2.62\end{array}$ & 1.36 & $>.05$ \\
\hline $\begin{array}{l}\text { Trial of Last } \\
\text { Error }\end{array}$ & $\stackrel{M}{S D}$ & $\begin{array}{r}44.15 \\
4.28\end{array}$ & $\begin{array}{r}36.53 \\
9.83\end{array}$ & .56 & $>.05$ \\
\hline $\begin{array}{l}\text { Longest Run } \\
\text { of Avoidances }\end{array}$ & $\begin{array}{r}M \\
\text { SD }\end{array}$ & $\begin{array}{l}8.30 \\
3.55\end{array}$ & $\begin{array}{r}17.26 \\
7.79\end{array}$ & 1.85 & $>.05$ \\
\hline $\begin{array}{l}\text { Number of } \\
\text { Reversals }\end{array}$ & $\begin{array}{l}\text { M } \\
\text { SD }\end{array}$ & $\begin{array}{r}15.05 \\
3.94\end{array}$ & $\begin{array}{r}11.26 \\
4.74\end{array}$ & .82 & $>.05$ \\
\hline
\end{tabular}

better than expected, an outcome tending to obscure the merits of the SOW arrangement. Moyer and Chapman (1966), by comparison, found that shuttle Ss given conventional continuous shock had only reached a $30 \%$ avoidance level after 50 trials whereas our Ss were avoiding almost $80 \%$ of the time at a comparable stage of training. It appeared as though, in at tempting to equate the auditory cues received by the SOW and Shuttle Ss, we had introduced conditions that led to a considerable improvement in the performance of the shuttle-box task.

\section{EXPERIMENT 2}

The second experiment was run in an attempt to determine whether the superiority of the SOW animals relative to the shuttle Ss could be increased by procedures designed to reduce the tendency of the SOW rats to resist the withdrawal of the black box and by eliminating the auditory cues that had been presented to the shuttle Ss. Such cues are typically absent from the shuttle-box situation.

\section{Method}

The Ss were 40 female hooded rats, 102 to 110 days old, from the Psychology Department colony. They were randomly assigned, 20 per group, to either the SOW or the Shuttle condition. Two rats in the SOW condition were discarded due to equipment failure and were replaced by new Ss.

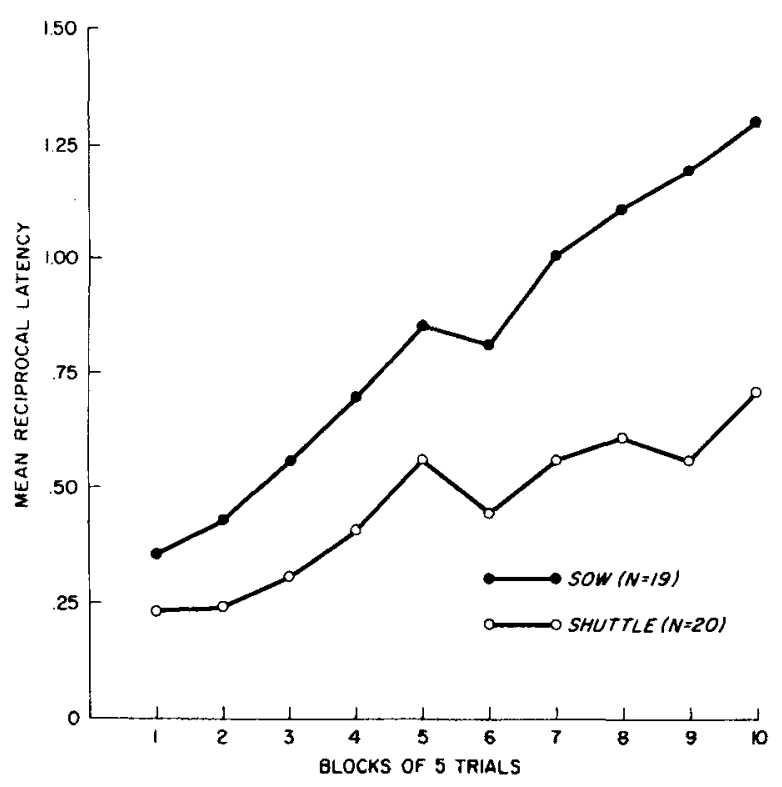

Fig. 3. Mean reciprocal latencies in Experiment 1 for the SOW and Shuttle groups over trials. 


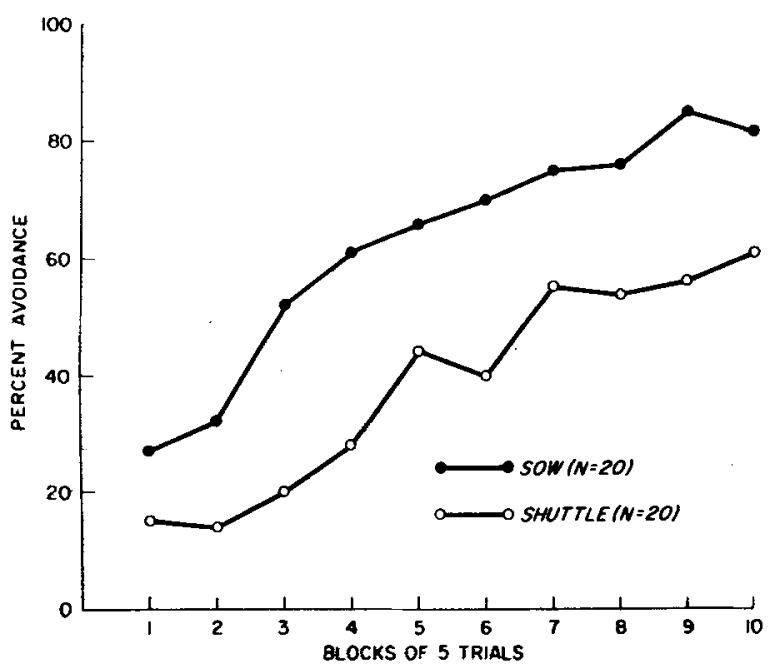

Fig. 4. The per cent of avoidances in Experiment 2 for the SOW and Shuttle groups over trials.

The procedures were the same as those of Experiment 1 except for the exceptions noted below. For the SOW condition, the doors started up simultaneously with the withdrawal of the box containing $S$ rather than after a 4-sec delay as in Experiment 1. Also, the floors of both black compartments were covered with a clear Teflon tape to make it more difficult for $S$ to resist the withdrawal of the floor. Both these changes were instituted to reduce the competing "box fighting" behavior observed in Experiment 1. In the Shuttle condition, the in-and-out movement of the box opposite to $S$ was eliminated. Thus, at the end of the $30-\sec$ ITI, the lights and tone came on at the instant the doors started up, and shock onset occurred 5 sec later.

\section{Results}

The means and standard deviations for both groups on four measures of avoidance learning are presented in Table 2. The SOW animals showed significantly more consecutive avoidances in their longest run of avoidances relative to the Shuttle animals. All other comparisons failed to reach conventional levels of significance, but as in Experiment 1, all differences were in the expected direction. Thus, the SOW Ss tended to make their first avoidance earlier in the session and also made fewer reversals than the Shuttle Ss. The Shuttle animals made their last error later in the training session than the SOW rats.

The per cent avoidance data are presented in Fig. 4. The SOW group clearly performed better than the Shuttle goup throughout training. An analysis of variance indicated that the effects of Groups $(F=8.31$, df $=1 / 38, p<.01)$ and Trials $(F=27.43, \quad d f=9 / 342, p<.001)$ were significant, but their interaction was not. While the curve for the SOW group was very similar to that obtained in Experiment 1, the Shuttle group curve did not reach as high a level after 50 trials (61\% avoidances in Experiment 2 compared to $84 \%$ avoidances in Experiment 1). Fig. 5 presents the mean reciprocal latency data. Analysis of variance revealed that only the Trials effect $(F=16.02$, $\mathrm{df}=9 / 342, \mathrm{p}<.001$ ) was significant. In contrast, in Experiment 1, the SOW group responded faster than the Shuttle group throughout training (Fig. 3).

\section{Discussion}

Whereas the SOW group in Experiment 2 avoided about as frequently as did the SOW animals in Experiment 1, the reaction
Table 2

Means and Standard Deviations

\begin{tabular}{|c|c|c|c|c|c|}
\hline & & $\begin{array}{l}\text { Shuttle } \\
\text { Training }\end{array}$ & $\begin{array}{c}\text { Simulated } \\
\text { One-Way }\end{array}$ & $t$ & $\mathbf{P}$ \\
\hline Subjects & $\mathbf{N}$ & 20 & 20 & & \\
\hline $\begin{array}{l}\text { Trial of First } \\
\text { Avoidance }\end{array}$ & $\begin{array}{l}\mathrm{M} \\
\mathrm{SD}\end{array}$ & $\begin{array}{l}13.70 \\
14.15\end{array}$ & $\begin{array}{l}6.95 \\
7.49\end{array}$ & 1.32 & $>.05$ \\
\hline $\begin{array}{l}\text { Trial of Last } \\
\text { Error }\end{array}$ & $\begin{array}{l}\mathrm{M} \\
\mathrm{SD}\end{array}$ & $\begin{array}{r}44.80 \\
6.47\end{array}$ & $\begin{array}{l}31.00 \\
15.62\end{array}$ & 1.05 & $>.05$ \\
\hline $\begin{array}{l}\text { Longest Run } \\
\text { of Avoidances }\end{array}$ & $\begin{array}{r}\text { M } \\
\text { SD }\end{array}$ & $\begin{array}{l}7.40 \\
6.10\end{array}$ & $\begin{array}{l}20.95 \\
13.64\end{array}$ & 2.21 & $<.05$ \\
\hline $\begin{array}{l}\text { Number of } \\
\text { Reversals }\end{array}$ & $\begin{array}{r}\mathrm{M} \\
\mathrm{SD}\end{array}$ & $\begin{array}{r}13.20 \\
6.72 \\
\end{array}$ & $\begin{array}{l}9.65 \\
6.34 \\
\end{array}$ & .82 & $>.05$ \\
\hline
\end{tabular}

latencies of the former Ss were longer. Apparently the programming changes, though introduced in an effort to improve performance, had a detrimental effect upon latencies. In the second experiment the raising of the doors and the withdrawal of the black box occurred simultaneously and the rats tended to "ride the box" back for a moment before avoiding. In contrast, in Experiment 1 the box was withdrawn completely before the doors were raised and the Ss tended to wait directly in front of the guillotine doors and to avoid as quickly as possible after the doors began to rise.

A comparison of the performance of the Shuttle Ss of the two experiments reveals that the elimination of the auditory and vibratory cues in the second study reduced the frequency of avoidance response but did not affect latencies. Presumably, the added cues provided by the box movements in the first experiment helped to prepare $S s$ to respond a few seconds later when the CS and tone were turned on. The sequential combination of box-movement cues and the CS complex constituted a serial CS, an arrangement known to facilitate shuttle-box avoidance responding (Kostanek \& Sawrey, 1965; Levis, 1966).

The SOW rats in both studies were generally superior to the shuttle Ss, this was presumably due to the fact that the appearance of the "start" box was quite distinctive relative to the "goal" box and was essentially the same regardless of its location on any given trial. The failure of both SOW groups to perform as well as Ss in nonautomated one-way devices can probably be ascribed to the presence of numerous extra-maze stimuli in both the auditory and visual modalities. As Olton and Isaacson (1968)

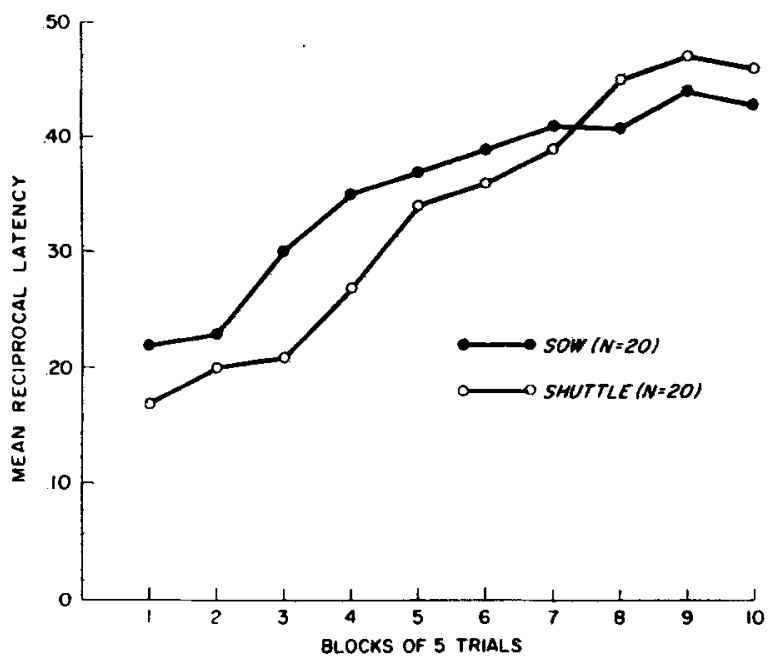

Fig. 5. Mean reciprocal latencies in Experiment 2 for the SOW and Shuttle groups over trials. 
have shown, the rat is rather sensitive to the influence of such cues and they often take precedence over intra-maze stimuli.

One possible disadvantage of the present apparatus should be mentioned. A few Ss in the SOW group of each experiment were observed to strenuously oppose box withdrawal throughout training by wedging themselves into the corner between the fixed end wall and the moving floor and side walls. These Ss seldom avoided. Many other Ss displayed such resistance on early trials, but abandoned this behavior as they began to avoid. It is possible that the elimination of this maladaptive behavior would result in performance more closeiy approximating that obtained with unautomated one-way avoidance tasks.

\section{REFERENCES}

BAUM, M. An automated apparatus for the avoidance training of rats. Psychological Reports, 1965, 16, 1205-1211.

BAUM, M., \& BOBROW, S. A. An automated analogue of the one-way Miller-type avoidance box. Psychonomic Science, 1966, 5, 361-362.

BEECROFT, R. S., \& BOUSKA, S. A. Acquisition of avoidance running in the rat. Psychonomic Science, 1967, 9, 163-164.

BRUSH, F. R. On the differences between animals that learn and do not le arn to avoid electric shock. Psychonomic Scienœ, 1966, 5, 123-124.

KOSTANEK, D. J., \& SAWREY, J. M. Acquisition and extinction of shuttlebox with complex stimuli. Psychonomic Science, 1965, 3, 369-370.

LEVIS, D. J. Implosive therapy: The subhuman analogue, the strategy, and the technique. In S. G. Armitage (Ed.), Behavior modification techmiques in the treatment of emotional disorders. Battle Creck. Michigan: V. A. Publication, 1966.

McCLEARY, R. A. Response-modulating functions of the limbic system: Initiation and suppression. In E. Stellar \& J. M. Sprague (Eds.), Progress in physiological psychology. New York: Academic Press, 1966.

MILLER, N. E. Experimental studies of conflict. In J. McV. Hunt (Ed.), Personality and the behavior disorders. Vol. 1. New York: Ronald Press. 1944.

MOYER, K. E., \& CHAPMAN, J. A. Effect of continuous vs. discontinuous shock on shuttle box avoidance in the rat. Psychonomic Science, 1966, 4, 197-198.

MOYER, K. E., \& KORN, J.H. Effect of UCS intensity on the acquisition and extinction of an avoidance response. Joumal of Experimental Psychology, 1964, 67, 352-359.

OLTON, D. S., \& ISAACSON, R. L. Importance of spatial location in active avoidance tasks. Journal of Comparative \& Physiological Psychology, 1968, 65, 535-539.

TENEN, S. S. An automated one-way avoidance box for the rat Psychonomic Science, 1966, 6, 407-408.

THEIOS, J. Simple conditioning as two-stage all-or-none learning. Psychological Review, 1963, 70, 403-417.

THEIOS, J., \& DUNAWAY, J. E. One-way versus shuttle avoidance conditioning. Psychonomic Science, 1964, 1, 251-252.

NOTE

1. Supported in part by Public Health Service Research Grant No. 5 RO1 MH11734-04 to Judson S. Brown.

\section{A photoelectric sound-activated relay}

\section{ROBERT ADAMSON and LEVIE McNAB, FLORIDA ATLANTIC UNIVERSITY, Boca Raton, Fla. 33432}

By activating photocell control circuits by a low voltage lamp in parallel with speaker outputs on conventional recorders, it is possible to obtain reliable and inexpensive program capability.

For purposes of coupling relay activation with amplified sound pulses, it is possible to use the voltage generated across the speaker output of the source. This, of course, varies depending on degree of amplification; however, recordings of a human voice (approximately $60 \mathrm{~dB}$ ) from two sources (a Nurelco tape recording and an Audograph record) yielded voltages up to 4 across speaker terminals. These could easily have been exceeded with increased amplification during recording.

Although voltages in this range could be amplified, in turn, to operate standard relays, the same effect may be reached by the interposition of a low voltage lamp and a photocell in the circuit.

Selection of lamp voltage is arbitrary, although it should not be grossly exceeded by the output voltage generated by the sound. If recordings are made at low level, with little ambient noise. the output voltage will be correspondingly low. In any event, it is possible to measure the peak output after recording and to choose a lamp of roughly corresponding voltage. The device described here used a standard 3-V flashlight lamp, in parallel with an 8-ohm speaker (not necessary unless sound is desired).

The function of the lamp is simply to activate a photocell that controls the relay circuit. Fig. 1 shows the photocell placed in series with the control relay. The RCA SQ 2521 photocell has a light resistance of $350 \mathrm{ohms}$, and is rated at $250 \mathrm{~V}$ ac or dc, $20 \mathrm{~W}$ demand, or $0.2 \mathrm{~W}$ continuous. The control relay is a Sigma 97638, SPST $115 \mathrm{~V}$ ac, with a 5000-ohm coil. This imposes a rating of about $.06 \mathrm{~W}$ on the cell. Other relays may be used if different functions are desired. For example, with a latching relay, such as the Potter and Brumfield GM 11AL11, one pulse might be used to close the circuit, and the next pulse to open it. Such relays may also be used for flip-flop application. The cited relay need not be on continuously and, hence, would not exceed the power rating of the cell.

The lamp and photocell are enclosed in a light-tight box that prevents triggering of the circuit by ambient light.

With a conventional four-track tape recorder, e.g., the Norelco 401 , it is possible to program two relays by recording sound pulses on Tracks 1 and 3 , or 2 and 4 , and playing back on stereo to two speaker outputs. This technique allows the use of basic logic programs, such as OR, AND, and holding circuits. It also makes it possible to cue visual presentations on one track along with audio on the other.

Within the ranges tested, that is, a $2 . \mathrm{V}$ to $5 . \mathrm{V}$ output from the speaker terminals, introduction of the lamp caused a voltage drop of approximately $25 \%$. With impedance matching of the sound source and the speaker, sound attenuation was not excessive ( $5 \mathrm{~dB}$ from a top of $95 \mathrm{~dB}$, sound pressure level). Changes in lamp resistance as a result of heating had no material effect. Thus, if it is desired to keep the speaker in the circuit, simultaneous relay keying and audio presentation is feasible.

The circuit, excluding the sound source, is inexpensive (less than $\$ 10.00$ ) and reliable.

\section{NOTE}

1. This research was supported by the Air Force Office of Scientific Research, Grant No. 1163-66.

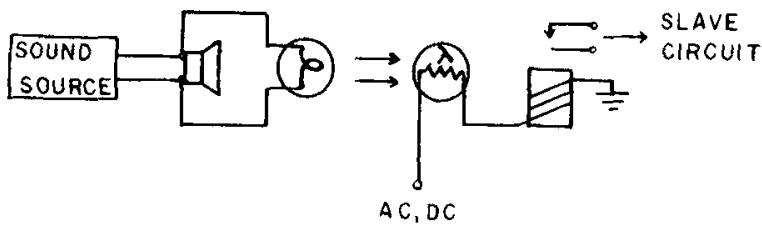

Fig. 1. Basic activation circuit with speaker included. 